\title{
Ultraviolet Radiation Emissions and Illuminance in Different Brands of Compact Fluorescent Lamps
}

\author{
Shahram Safari, ${ }^{1}$ Sina Eshraghi Dehkordy, ${ }^{1}$ Meghdad Kazemi, \\ Habibollah Dehghan, ${ }^{1}$ and Behzad Mahaki ${ }^{3}$ \\ ${ }^{1}$ Department of Occupational Health Engineering, School of Health, Isfahan University of Medical Sciences, Isfahan, Iran \\ ${ }^{2}$ Department of Occupational Health Engineering, School of Health, Ilam University of Medical Sciences, Ilam, Iran \\ ${ }^{3}$ Department of Statistics and Epidemiology, School of Health, Isfahan University of Medical Sciences, Isfahan, Iran \\ Correspondence should be addressed to Habibollah Dehghan; ha_dehghan@hlth.mui.ac.ir
}

Received 25 July 2014; Revised 18 December 2014; Accepted 1 January 2015

Academic Editor: Rajaram S. Mane

Copyright (c) 2015 Shahram Safari et al. This is an open access article distributed under the Creative Commons Attribution License, which permits unrestricted use, distribution, and reproduction in any medium, provided the original work is properly cited.

\begin{abstract}
Introduction. Replacing incandescent lamps with compact fluorescent lamps (CFLs), which are three to six times more efficient, is one of the easiest methods to achieve energy efficiency. The present study aimed to evaluate relationships between UV emissions radiated and illuminance CFLs. Material and Methods. This pilot study was conducted on 16 single envelope CFLs. The illuminance and UV irradiance of various types of CFLs are measured on a three-meter long optical bench, using a calibrated lux meter and UV meter, and measurement was done in $10,25,50,100,150$, and $200 \mathrm{~cm}$, in three angles, including $0^{\circ}, 45^{\circ}$, and $90^{\circ}$, at the ages of 0,100 , and 2000 hours. Result. UVC irradiance was not observed at the distance of $10 \mathrm{~cm}$ in all of lamps. The lowest value of UVB irradiance was recorded in Pars Khazar lamp, while the highest value was recorded in Etehad lamps. UVR values measured at different times showed negligible differences; the highest asset value was detected in zero times. One way ANOVA indicated that relationships between UVA irradiance and illuminance were significant $(P<0.05)$. Conclusion. UVB irradiance in most of the lamp in 10 and $25 \mathrm{~cm}$ was more than occupational exposure and UVA except for the fact that Pars Khazar 60 watts and Nama Noor 60 watts were less than occupational exposure.
\end{abstract}

\section{Introduction}

The amount of energy used for lighting will be $80 \%$ higher in 2030 than today [1]. And Lighting is responsible for $19 \%$ of the electricity consumption [2]. On the other hand, one of the most important technologies in this century is energy saving that is an important item among the concept of environmental protection, economy, and improved science and technology [3]. There are various energy-saving products and compact fluorescent lamp (CFLs) is one of these products. Lighting energy can be saved in many ways, including (I) improving the efficiency of the light source; (ii) improving the efficiency of the specific component of lighting system, typically the ballast; (iii) improving the efficiency of the luminaries [4]. Replacing incandescent lamps with CFLs which have played an important role in both industrial and domestic lighting is one of the most obvious and easiest methods to achieve energy efficiency [5]. Replacing technology can occur at a very low cost and provide immediate results [2]. CFLs are three to six times more efficient than incandescent lamps [6]. Egypt, Iran, Saudi Arabia, and Turkey are the largest consumers of electricity. These four countries consume about $88 \%$ of the region's total electricity consumption, who have a very aggressive current program to promote CFLs. In Iran, the Ministry of Energy has developed 20 different strategic goals, including the distribution of 93 million high-efficiency lamps for 21 million households. Using various distribution methods, about 65 million CFLs have been distributed to households up until the year 2009. This resulted in a reduction of $1750 \mathrm{MW}$ (megawatt) of peak load, annual electricity saving of 3.8 Twh (terawatt-hour), and the reduction of $2.7 \mathrm{Mt}$ (million tons) of $\mathrm{CO} 2$ [2].

CFLs have many disadvantages. One of these emits higher acceptable levels of UV radiation [7]. Fluorescent light 
bulbs contain mercury, and the inside of the tube is coated with phosphors; the mercury gas inside the tube becomes excited when the electric current is switched on which emits UV radiation. This UV radiation then interacts with the chemicals on the inside of the bulb to generate light. Ideally, conversion of UV to visible light should be $100 \%$; however, due to the defect in phosphor it contains trace amount of UV radiation [8-13].

Ultraviolet (UV) radiation is a form of electromagnetic radiation on the electromagnetic spectrum, UV radiation comes between visible light and X-ray. UV radiation is based on its effect on living tissue, and wavelength is divided into three major groups: UVA (320-400 nm), UVB (290-320), and UVC (200-290) [14, 15].

The acute and chronic effects are the normal responses of the skin to UVR; acute reactions considered will be erythema (sunburn) and vitamin D production. Skin aging and skin cancer will be discussed as those reactions produced by prolonged or repeated UVR exposure.

Erythema induced by CFLs is strongly dependent on the wavelength of radiation. At $300 \mathrm{~nm}$ an average threshold dose or minimal erythema dose (MED) is about $10-20 \mathrm{~mJ} \cdot \mathrm{cm}^{-2}$ whereas for UVA radiation the MED is about a thousandfold higher. Large doses of UVB may result in oedema, pain, and blistering although blistering never occurs with UVC [16].

Cole et al. demonstrated that CFLs emitted significant levels of UVB and UVC [8]. In 2004, Sayre et al. made quantitative measurements of UV emission from CFLs commonly used at home and in the workplace. His results show that all emitted appreciable levels of UVA and UVB, and several even emitted UVC [10].

Light output in the CFLs is influenced by the mercury vapor pressure inside the lamp; if the pressure is either greater than or less than optimal, light output declines, and change in contain mercury vapor can change light output [17]. In relation to the illuminance and ultraviolet radiation from compact fluorescent lamps and general lighting service (GLS) a study by Khazova and O'Hagan carried out that the results show in equal illuminance 500 lux for both lamps UVA for CFL and GLS was $0.05 \mathrm{w} / \mathrm{m}^{2}$ and $0.03 \mathrm{w} / \mathrm{m}^{2}$, for UVB in CFL and GLS was $0.004 \mathrm{w} / \mathrm{m}^{2}$ and $0.001 \mathrm{w} / \mathrm{m}^{2}$, respectively [18]. In typical practical conditions, the illuminance under CFLs is 500 lux and 10,000 lux outdoors in natural daylight. In this condition UVA for CFL and natural daylight was $0.05 \mathrm{w} / \mathrm{m}^{2}$ and $5.4 \mathrm{w} / \mathrm{m}^{2}$, for UVB in CFL and natural daylight was $0.004 \mathrm{w} / \mathrm{m}^{2}$ and $0.08 \mathrm{w} / \mathrm{m}^{2}$, respectively. Here the illuminance increases and the amount of UV radiations also increases [18].

Because of increasing the cost of electricity in recent years people use CFLs that consume 3-6 times less energy relative to incandescent lamps and because of nature of produced light in CFLs, ultraviolet radiation is generated and light output in the CFLs is influenced by the mercury vapor pressure inside the lamp, as change in contain mercury vapor can change light output and UV irradiance; the present study aimed to evaluate relationships between UV emissions radiated and illuminance from compact fluorescent lamps.

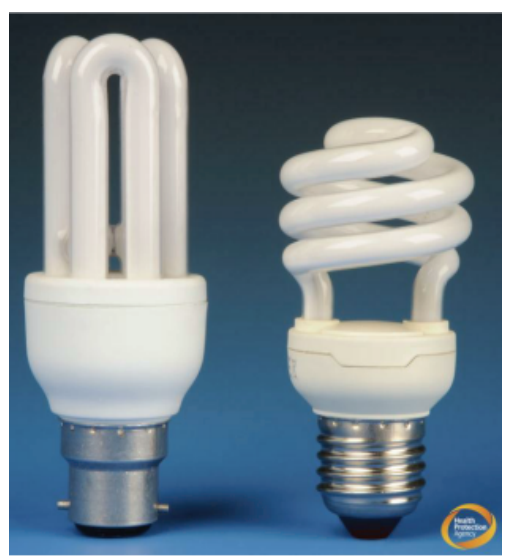

FIgURE 1: Single envelope CFLs.

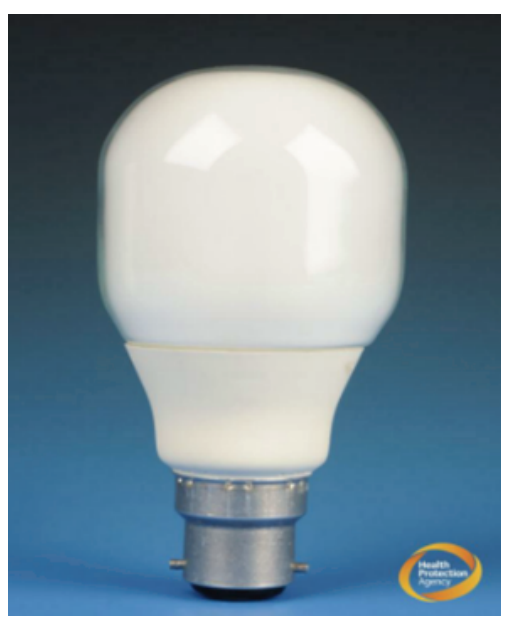

FIGURE 2: Shield envelop CFLs.

\section{Material and Methods}

This pilot study was conducted on 16 CFLs that were randomly purchased from local retail outlets in Isfahan City, Isfahan, Iran. The light sources were manufactured by four manufacturers, including branded names and retailer owned brands. The CFLs were marked as 11, 18, 40, and 60 watts and all of the lamps contained integral electronic ballasts.

In this study, all of light sources were open (or single envelope) CFLs (Figure 1) and "shielded" refers to CFL that was completely enclosed within a bulb-shaped shield during the manufacturing process (Figure 2).

The illuminance and UV irradiance of various types of CFLs are measured on a three-meter long optical bench, using a calibrated lux meter and UV meter (Figure 3), and measurement was done in $10,25,50,100,150$, and $200 \mathrm{~cm}$, in three angles, including $0^{\circ}, 45^{\circ}$, and $90^{\circ}$, at the ages of 0,100 , and 2000 hours [19]. In the angle $0^{\circ}$ the lamps were orientated horizontally so that the tip of the lamp was facing the input diffuser of the UV and lux meter. This was to measure the radiation one might expect to receive if standing directly under a lamp suspended from the ceiling. In the angles $45^{\circ}$ 
TABLE 1: UVB irradiance $\left(\mathrm{W} \cdot \mathrm{m}^{-2}\right)$ in different times for four brand CFLs at $90^{\circ}$ in Iranian brands.

\begin{tabular}{|c|c|c|c|c|c|c|c|c|c|c|c|c|c|}
\hline \multirow{2}{*}{ Brand of CFLs } & \multirow{2}{*}{$\begin{array}{c}\text { Distance }(\mathrm{cm}) \\
\text { Measurement time (hour) }\end{array}$} & \multicolumn{3}{|c|}{10} & \multicolumn{3}{|c|}{25} & \multicolumn{3}{|c|}{50} & \multicolumn{3}{|c|}{100} \\
\hline & & 0 & 100 & 2000 & 0 & 100 & 2000 & 0 & 100 & 2000 & 0 & 100 & 2000 \\
\hline \multirow{4}{*}{ Pars khazar } & $11 \mathrm{~W}$ & 0.01 & 0 & 0 & 0.01 & 0 & 0 & 0 & 0 & 0 & 0 & 0 & 0 \\
\hline & $18 \mathrm{~W}$ & 0.01 & 0.02 & 0.01 & 0.01 & 0 & 0 & 0.01 & 0 & 0 & 0 & 0 & 0 \\
\hline & $40 \mathrm{~W}$ & 0.02 & 0.02 & 0.01 & 0.01 & 0 & 0 & 0 & 0 & 0 & 0 & 0 & 0 \\
\hline & $60 \mathrm{~W}$ & 0.01 & 0 & 0 & 0 & 0 & 0 & 0 & 0 & 0 & 0 & 0 & 0 \\
\hline \multirow{4}{*}{ Parmis } & $11 \mathrm{~W}$ & 0 & 0.01 & 0 & 0 & 0.01 & 0 & 0 & 0 & 0 & 0 & 0 & 0 \\
\hline & $18 \mathrm{~W}$ & 0.01 & 0.01 & 0.01 & 0 & 0 & 0 & 0 & 0 & 0 & 0 & 0 & 0 \\
\hline & $40 \mathrm{~W}$ & 0.01 & 0.02 & 0.01 & 0 & 0 & 0 & 0 & 0 & 0 & 0 & 0 & 0 \\
\hline & $60 \mathrm{~W}$ & 0.01 & 0 & 0 & 0.01 & 0 & 0 & 0 & 0 & 0 & 0 & 0 & 0 \\
\hline \multirow{4}{*}{ Etehad } & $11 \mathrm{~W}$ & 0 & 0 & 0 & 0 & 0 & 0 & 0 & 0 & 0 & 0 & 0 & 0 \\
\hline & $18 \mathrm{~W}$ & 0.01 & 0.01 & 0.01 & 0 & 0.01 & 0 & 0 & 0.01 & 0 & 0 & 0 & 0 \\
\hline & $40 \mathrm{~W}$ & 0.01 & 0.02 & 0 & 0.01 & 0 & 0 & 0 & 0 & 0 & 0 & 0 & 0 \\
\hline & $60 \mathrm{~W}$ & 0.02 & 0.02 & 0 & 0.01 & 0 & 0.01 & 0.01 & 0 & 0 & 0 & 0 & 0 \\
\hline \multirow{4}{*}{ Nama Noor } & $11 \mathrm{~W}$ & 0.01 & 0.01 & 0 & 0 & 0 & 0 & 0 & 0 & 0 & 0 & 0 & 0 \\
\hline & $18 \mathrm{~W}$ & 0.01 & 0.01 & 0 & 0.01 & 0.01 & 0 & 0 & 0 & 0 & 0 & 0 & 0 \\
\hline & $40 \mathrm{~W}$ & 0.02 & 0.02 & 0 & 0.01 & 0 & 0 & 0 & 0 & 0 & 0 & 0 & 0 \\
\hline & $60 \mathrm{~W}$ & 0.02 & 0.02 & 0.01 & 0.01 & 0 & 0 & 0 & 0 & 0 & 0 & 0 & 0 \\
\hline
\end{tabular}

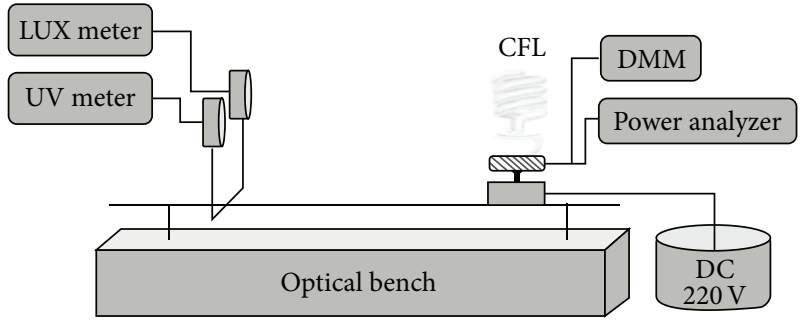

FIGURE 3: Schematic diagram of experimental set up for illuminance and UV irradiance measurement.

and $90^{\circ}$ for UV exposure from lamps used at desk or task lamps.

A type-666230 photometer-radiometer equipped with UVA, UVB, and UVC detectors was used to measure UV irradiance in all the three ranges and for illuminance measurement, a digital photometer types YF-170 was used. Measurements were performed in a dark room, maintaining the temperature at $(26 \pm 2)^{\circ} \mathrm{C}$ and the relative humidity (45\%). Following a 10-minute warm-up period, the emission spectrum of each lamp was measured. Measurements were repeated for each type of CFLs and finally averaged out.

Finally, the information was analyzed using SPSS-20. In order to compare UVA and UVB irradiance and the value and relationships between UV irradiance and illuminance in four brands in three angles, we used one-way ANOVA. A $P$ value less than 0.05 was considered to be statistically significant.

\section{Results}

UV irradiance and illuminance were measured at the different distance for sixteen types of CFLs of different wattage. At the distance of $10 \mathrm{~cm}$ that was considered to be the closest distance that people would be exposed to the lamp, even in the desk-top application UVC irradiance could not be detected in all the cases. For analyzing the UV content at the short distance, the measurements were conducted at the distance of $10 \mathrm{~cm}$.

Negligible amounts of UVA and UVB were detected at 150 and $200 \mathrm{~cm}$ from all CFLs. Therefore, only data relating to the UV irradiance measured at $10,25,50$, and $100 \mathrm{~cm}$ were analysed in this study.

In order to compare UV irradiance in three angles $(0,45$, and 90), one-way ANOVA indicated that difference between three angles was not significant statically $(P>0.05)$. The lowest amount was recorded in $45^{\circ}$; furthermore, in most cases the highest amount of UV irradiance was detected in $90^{\circ}$ but this difference was not significant statically.

Table 1 shows the UVB irradiance for four brands of CFLs; one-way ANOVA indicated that difference between UVB irradiance in the same wattage of four brands of lamps was not significant statistically $(P>0.05)$. The lowest value of UVB irradiance was recorded in Pars Khazar lamp, while the highest value was recorded in Etehad lamps. Table 2 shows the UVA irradiance $\left(\mathrm{w} \cdot \mathrm{m}^{-2}\right)$ values in $10,25.50$, and $100 \mathrm{~cm}$ for three measurement times, including 0, 100, and 2000 hours; as is obvious, UVA irradiance increased with the increase in lamp electrical wattage and emissions decreased rapidly with distance, but such cases are not found for UVB irradiance. UVR values measured at different times showed negligible differences; the highest values were detected in zero times. One-way ANOVA showed that this value for three times was not significant statistically. Pars khazar with the highest UVA irradiance placed in the first group and other groups were Nama Noor, Parmis, and Etehad, respectively.

To make a better comparison in UVR concentration, it would be more appropriate to compare UVA concentration relative to illuminance in four brands. As shown in Table 2 
TABLE 2: UVA irradiance $\left(\mathrm{W} \cdot \mathrm{m}^{-2}\right)$ and illuminance (lux) in different times for four brand CFLs in Iranian brands.

\begin{tabular}{|c|c|c|c|c|c|c|c|c|c|c|c|c|c|c|}
\hline \multirow{2}{*}{ Brand of CFLs } & \multirow{2}{*}{$\begin{array}{l}\text { Power } \\
\text { (watt) }\end{array}$} & \multirow{2}{*}{$\begin{array}{c}\text { Distance }(\mathrm{cm}) \\
\text { Measurement time (hour) }\end{array}$} & \multicolumn{3}{|c|}{10} & \multicolumn{3}{|c|}{25} & \multicolumn{3}{|c|}{50} & \multicolumn{3}{|c|}{100} \\
\hline & & & 0 & 100 & 2000 & 0 & 100 & 2000 & 0 & 100 & 2000 & 0 & 100 & 2000 \\
\hline \multirow{8}{*}{ Pars khazar } & \multirow{2}{*}{$11 \mathrm{~W}$} & UVA $\left(\mathrm{W} \cdot \mathrm{m}^{-2}\right)$ & 0.29 & 0.33 & 0.22 & 0.05 & 0.05 & 0.03 & 0.02 & 0.02 & 0 & 0.01 & 0 & 0 \\
\hline & & Illuminance (lux) & 6850 & 6580 & 6520 & 982 & 1012 & 1099 & 281 & 264 & 316 & 84 & 82 & 93 \\
\hline & \multirow{2}{*}{$18 \mathrm{~W}$} & UVA $\left(\mathrm{W} \cdot \mathrm{m}^{-2}\right)$ & 0.68 & 0.92 & 0.36 & 0.16 & 0.13 & 0.06 & 0.06 & 0.04 & 0.01 & 0.02 & 0.02 & 0 \\
\hline & & Illuminance (lux) & 9990 & 9880 & 6900 & 1476 & 1373 & 885 & 371 & 388 & 150 & 105 & 112 & 74 \\
\hline & \multirow{2}{*}{$40 \mathrm{~W}$} & UVA $\left(\mathrm{W} \cdot \mathrm{m}^{-2}\right)$ & 1.63 & 1.24 & 1.05 & 0.32 & 0.3 & 0.19 & 0.09 & 0.07 & 0.07 & 0.03 & 0.03 & 0 \\
\hline & & Illuminance (lux) & 13440 & 11490 & 13250 & 3320 & 3440 & 2890 & 784 & 707 & 689 & 206 & 214 & 166 \\
\hline & \multirow{2}{*}{$60 \mathrm{~W}$} & $\operatorname{UVA}\left(\mathrm{W} \cdot \mathrm{m}^{-2}\right)$ & 1.7 & 1.51 & 1.41 & 0.54 & 0.48 & 0.4 & 0.05 & 0.08 & 0.07 & 0.03 & 0.05 & 0.02 \\
\hline & & Illuminance (lux) & 14610 & 14650 & 14020 & 3550 & 2940 & 2880 & 921 & 731 & 680 & 266 & 209 & 180 \\
\hline \multirow{8}{*}{ Parmis } & \multirow{2}{*}{$11 \mathrm{~W}$} & $\mathrm{UVA}\left(\mathrm{W} \cdot \mathrm{m}^{-2}\right)$ & 0.19 & 0.13 & 0.12 & 0.04 & 0.04 & 0.01 & 0.02 & 0.02 & 0 & 0 & 0.02 & 0.01 \\
\hline & & Illuminance (lux) & 3870 & 3290 & 3030 & 657 & 598 & 499 & 189 & 165 & 36 & 60 & 49 & 34 \\
\hline & \multirow{2}{*}{$18 \mathrm{~W}$} & $\mathrm{UVA}\left(\mathrm{W} \cdot \mathrm{m}^{-2}\right)$ & 0.52 & 0.34 & 0.27 & 0.09 & 0.08 & 0.05 & 0.04 & 0.04 & 0.02 & 0.02 & 0.02 & 0 \\
\hline & & Illuminance (lux) & 9000 & 9350 & 8510 & 1330 & 1300 & 1240 & 501 & 466 & 361 & 142 & 126 & 103 \\
\hline & \multirow{2}{*}{$40 \mathrm{~W}$} & $\operatorname{UVA}\left(\mathrm{W} \cdot \mathrm{m}^{-2}\right)$ & 0.96 & 0.87 & 0.55 & 0.17 & 0.26 & 0.12 & 0.07 & 0.05 & 0.02 & 0.03 & 0.03 & 0 \\
\hline & & Illuminance (lux) & 12470 & 12340 & 12820 & 3820 & 3590 & 2680 & 837 & 865 & 697 & 243 & 225 & 194 \\
\hline & \multirow{2}{*}{$60 \mathrm{~W}$} & $\mathrm{UVA}\left(\mathrm{W} \cdot \mathrm{m}^{-2}\right)$ & 0.67 & 0.61 & 0.46 & 0.15 & 0.1 & 0.1 & 0.07 & 0.03 & 0.07 & 0.05 & 0.03 & 0 \\
\hline & & Illuminance (lux) & 13090 & 14590 & 10230 & 4253 & 3590 & 2660 & 689 & 921 & 587 & 266 & 261 & 167 \\
\hline \multirow{8}{*}{ Etehad } & \multirow{2}{*}{$11 \mathrm{~W}$} & UVA $\left(\mathrm{W} \cdot \mathrm{m}^{-2}\right)$ & 0.07 & 0.07 & 0.23 & 0.02 & 0.02 & 0.06 & 0.03 & 0.01 & 0 & 0.02 & 0.01 & 0 \\
\hline & & Illuminance (lux) & 3500 & 3170 & 3090 & 595 & 540 & 512 & 177 & 164 & 151 & 47 & 41 & 35 \\
\hline & \multirow{2}{*}{$18 \mathrm{~W}$} & $\mathrm{UVA}\left(\mathrm{W} \cdot \mathrm{m}^{-2}\right)$ & 0.36 & 0.24 & 0.21 & 0.1 & 0.07 & 0.03 & 0.07 & 0.03 & 0.01 & 0.03 & 0.02 & 0 \\
\hline & & Illuminance (lux) & 6860 & 6290 & 6020 & 1471 & 1076 & 1062 & 386 & 326 & 315 & 117 & 92 & 89 \\
\hline & \multirow{2}{*}{$40 \mathrm{~W}$} & $\mathrm{UVA}\left(\mathrm{W} \cdot \mathrm{m}^{-2}\right)$ & 0.54 & 0.38 & 0.31 & 0.13 & 0.12 & 0.05 & 0.6 & 0.04 & 0.01 & 0.03 & 0.03 & 0 \\
\hline & & Illuminance (lux) & 12340 & 10450 & 8630 & 3850 & 3400 & 3100 & 910 & 831 & 317 & 260 & 268 & 162 \\
\hline & \multirow{2}{*}{$60 \mathrm{~W}$} & $\mathrm{UVA}\left(\mathrm{W} \cdot \mathrm{m}^{-2}\right)$ & 0.97 & 0.89 & 0.26 & 0.33 & 0.2 & 0.15 & 0.09 & 0.05 & 0.03 & 0.04 & 0.04 & 0 \\
\hline & & Illuminance (lux) & 8050 & 11600 & 5220 & 3490 & 3060 & 2860 & 866 & 812 & 801 & 330 & 254 & 225 \\
\hline \multirow{8}{*}{ Nama Noor } & \multirow{2}{*}{$11 \mathrm{~W}$} & UVA $\left(\mathrm{W} \cdot \mathrm{m}^{-2}\right)$ & 0.41 & 0.21 & 0.13 & 0.07 & 0.05 & 0.04 & 0.02 & 0.03 & 0 & 0.01 & 0.02 & 0 \\
\hline & & Illuminance (lux) & 2920 & 2850 & 1640 & 520 & 554 & 513 & 210 & 162 & 153 & 56 & 49 & 30 \\
\hline & \multirow{2}{*}{$18 \mathrm{~W}$} & $\mathrm{UVA}\left(\mathrm{W} \cdot \mathrm{m}^{-2}\right)$ & 0.49 & 0.22 & 0.27 & 0.07 & 0.05 & 0.01 & 0.03 & 0.03 & 0 & 0.02 & 0.02 & 0 \\
\hline & & Illuminance (lux) & 3610 & 2390 & 2470 & 541 & 425 & 325 & 176 & 128 & 91 & 45 & 39 & 44 \\
\hline & & UVA $\left(\mathrm{W} \cdot \mathrm{m}^{-2}\right)$ & 1.01 & 0.7 & 0.27 & 0.18 & 0.14 & 0.04 & 0.07 & 0.04 & 0 & 0.03 & 0 & 0 \\
\hline & $40 \mathrm{VV}$ & Illuminance (lux) & 6640 & 5200 & 3470 & 1481 & 1001 & 484 & 378 & 260 & 148 & 100 & 81 & 24 \\
\hline & & UVA $\left(\mathrm{W} \cdot \mathrm{m}^{-2}\right)$ & 1.3 & 1.07 & 0.46 & 0.28 & 0.25 & 0.13 & 0.09 & 0.05 & 0.01 & 0.04 & 0.03 & 0 \\
\hline & & Illuminance (lux) & 9490 & 8460 & 4860 & 2560 & 2230 & 1057 & 601 & 812 & 328 & 180 & 157 & 40 \\
\hline
\end{tabular}

Pars khazar with the highest value of UVA emission also has the highest amount of illuminance, but Nama Noor with the lowest illuminance placed in second rank in UVA emission. One-way ANOVA indicated that relationships between UVA irradiance and illuminance were significant $(P<0.05)$.

\section{Discussion}

Measurements of UVR and illuminance irradiance from the CFLs were made in the ultraviolet and visible part of the spectrum $(100-780 \mathrm{~nm})$ at distances of 10, 25, 50, 100, 150, and $200 \mathrm{~cm}$. Techniques for the measurement of UVR may be divided into three classes: physical, chemical, and biological. The regions of ultraviolet radiation have widely been differing in physical properties and potential for causing biological damage [16], including the following: (i) UVA rays, which are the weakest of the UV rays, can cause skin cells to age and indirect damage to cells' DNA. (ii) UVB rays are slightly stronger. They can cause direct damage to the DNA, sunburns, and skin cancers. (iii) UVC rays are the strongest UV rays. Fortunately, they react with ozone do not reach the ground. But they can be found in some man-made sources, such as mercury lamps [20].

The standard for occupational exposure to ultraviolet radiation is based on the threshold limit values (TLV) published by the American conference of Governmental Industrial Hygienists. These TLV are relative to a monochromatic source of radiation at $270 \mathrm{~nm}$. The exposure at this wavelength in $8 \mathrm{~h}$ is $30 \mathrm{Jm}^{-2}$. In our study, measurable values of the UVC irradiance $(100 \mathrm{~nm}-280 \mathrm{~nm})$ were not observed 
using UVC detectors at the distance of $10 \mathrm{~cm}$ in all of lamps that is consistent to study by Khazova and O'Hagan that stated, "Radiation below $280 \mathrm{~nm}$ (UVC) is not received at the earth's surface and is not emitted by tubular fluorescent and incandescent lamps for general lighting purposes." But in another study by Khazova and O'Hagan on 73 CFLs (20 single envelopes and 53 double envelope CFLs) at $2 \mathrm{~cm}$ and $20 \mathrm{~cm}$, a result of measurement showed single envelope lamps emitted UVC and they concluded that the UVC irradiance was probably due to defects in the phosphor coating of the glass envelope [18].

As is denoted the lowest and highest UV emission were recorded in $45^{\circ}$ and $90^{\circ}$ angle, respectively. The similar results reported by Roisin et al. and Safari et al. concluded that CFLs radiate more horizontally $\left(90^{\circ}\right)$ at the expense of the vertical intensity $\left(0^{\circ}\right)[13,21]$.

All of light sources emitted UV in regions UVA and UVB; the amount of emissions varied randomly between different bulbs and different manufacturers. According to occupational exposure limited (OEL), occupational UVB and UVA exposure should be limited to an effective irradiance of 0.000003 and $1.04166 \mathrm{~W} \cdot \mathrm{m}^{-2}$ in an $8 \mathrm{~h}$ period, respectively $[22,23]$.

At $10 \mathrm{~cm}$ distance, measurement UVB irradiance from most of CFLs was more than OEL. The highest value was recorded in Etehad lamp with $0.03 \mathrm{~W} \cdot \mathrm{m}^{-2}$ that was 10000 times more than OEL.

Among sixteen CFLs which was measured at a distance of $10 \mathrm{~cm}$, the UVA output for Pars Khazar 40 and 60 watts was $1.61 \mathrm{~W} \cdot \mathrm{m}^{-2}$ and $1.78 \mathrm{~W} \cdot \mathrm{m}^{-2}$, respectively, and for Nama Noor, $60 \mathrm{~W}$ was $1.3 \mathrm{~W} \cdot \mathrm{m}^{-2}$; this shows that three CFLs would exceed the UVA exposure limit in $8 \mathrm{~h}$ at a distance of $10 \mathrm{~cm}$. Study by Mironava et al. indicated that UV irradiance was different between bulbs and different manufacturers, and the result from that study showed UVR in different distance in many cases was exceeded of occupational exposure limited [24].

Rihner and McGrath (1992) conducted a survey of systemic lupus erythematosus (SLE) patients. They reported a substantial number who recalled having experienced symptom flares after exposure to fluorescent light [25]. The risk of death in middle-aged adults from occupational exposure to fluorescent lighting for basal and squamous cell carcinomas is 1 in 2.5 million per year [26].

\section{Conclusion}

UV emission (UVA, UVB, and UVC) and illuminance $(100 \mathrm{~nm}-780 \mathrm{~nm})$ were measured from different brands, size, and electrical powers of CFLs. UVC emissions were not observed at the distance of $10 \mathrm{~cm}$ in all of lamps. UVB irradiance in most of the lamp in 10 and $25 \mathrm{~cm}$ was more than occupational exposure. The highest values were measured in Etehad lamps while of all the bulbs tested, in UVA irradiance, the Etehad appeared to be the safest. Nama Noor with the lowest illuminance has more value of UVA. As is denoted this study carried out on single envelope CFLs; in some cases the amount of UVR was more than OEL; in order to decrease
UVR there are two methods: (i) shielded fluorescent lamps by acrylic diffusers and (ii) double envelope lamp.

As Elwood (1986) noted, it has generally proved impossible even to specify whether the fluorescent lamps were shielded by acrylic diffusers or not; if they were, then the ultraviolet exposure of people in those spaces was negligible because of the absorptive properties of acrylic [27].

In order to compare the UV radiation from double and single envelope a study was conducted by Khazova and O'Hagan in which the double envelope lamp has very low level of UVB emission, with the spectrum cut-off below $313 \mathrm{~nm}$, whereas some of single envelope lamps emit in the UVB and UVC $(254 \mathrm{~nm})$ regions, probably due to defects in the phosphor coating [18].

\section{Conflict of Interests}

The authors declare that they have no conflict of interests.

\section{Acknowledgments}

The authors would like to thank the experts of Physical Agent Laboratory for cooperation in UV measuring. This study was financially supported by Vice President for research in Isfahan University of Medical Sciences (Project no. 291021).

\section{References}

[1] C. Mandil, Light's Labour's Lost: Policies for Energy-Efficient Lighting, vol. 343, Energy World, 2006.

[2] I. Abdel Gelil, "Regional report on efficient lighting in the Middle East and North Africa," Tech. Rep., Division of Global Environment Facility Coordination, United Nations Environment Programme, Nairobi, Kenya, 2011.

[3] "General discussion on energy saving," in Proceedings of the 1st International Conference on Power Electronics Systems and Applications, D. H. Wang and K. W. E. Cheng, Eds., pp. 298303, IEEE, November 2004.

[4] C. Figueres and M. Bosi, Achieving Greenhouse Gas Emission Reductions in Developing Countries through Energy Efficient Lighting Projects in the Clean Development Mechanism (CDM), The Carbon Finance Unit, World Bank, Washington, DC, USA, 2006.

[5] P. Waide and S. Tanishima, Light's Labour's Lost: Policies for Energy-Efficient Lighting, OECD Publishing, 2006.

[6] T. Harris, How fluorescent lamps work, 2001, http://home.howstuffworks.com/fluorescent-lamp.htm.

[7] D. Parsons, "The environmental impact of compact fluorescent lamps and incandescent lamps for Australian conditions," The Environmental Engineer, vol. 7, no. 2, pp. 8-14, 2006.

[8] C. Cole, P. D. Forbes, R. E. Davies, and F. Urbach, "Effect of indoor lighting on normal skin," Annals of the New York Academy of Sciences, vol. 453, pp. 305-316, 1985.

[9] A. D. Nuzum-Keim and R. D. Sontheimer, "Ultraviolet light output of compact fluorescent lamps: comparison to conventional incandescent and halogen residential lighting sources," Lupus, vol. 18, no. 6, pp. 556-560, 2009.

[10] R. M. Sayre, J. C. Dowdy, and M. Poh-Fitzpatrick, "Dermatological risk of indoor ultraviolet exposure from contemporary 
lighting sources," Photochemistry and Photobiology, vol. 80, no. 1, pp. 47-51, 2004.

[11] M. J. Whillock, A. F. McKinlay, J. Kemmler, and P. G. Forsgren, "Ultraviolet radiation emissions from miniature (compact) fluorescent lamps," Lighting Research and Technology, vol. 22, no. 2, pp. 125-128, 1990.

[12] M. Havas, Health Concerns Associated with Energy Efficient Lighting and Their Electromagnetic Emissions, vol. 3, SCENIHR \& Light Sensitivity, 2008.

[13] S. Safari, M. Kazemi, H. A. Yousefi, H. Dehghan, and B. Mahaki, "Evaluation of ultra violet emissions radiated from compact fluorescent lamps of Iranian current brands," Health Scope, vol. 2, no. 3, pp. 130-135, 2013.

[14] ACGIH, TLVs and BEIs Based on the Documentation of the Threshold Limit Values for Chemical Substances and Physical Agents, and Biological Exposure Indices, ACGIH, Cincinnati, Ohio, USA, 2008.

[15] B. L. Diffey, "Sources and measurement of ultraviolet radiation," Methods, vol. 28, no. 1, pp. 4-13, 2002.

[16] B. L. Diffey, "Ultraviolet radiation physics and the skin," Physics in Medicine and Biology, vol. 25, no. 3, pp. 405-426, 1980.

[17] National Lighting Product Information Program, "Screwbase compact fluorescent lamp products," Specifier Reports, vol. 7, no. 1, p. 4, 2005.

[18] M. Khazova and J. B. O’Hagan, "Optical radiation emissions from compact fluorescent lamps," Radiation Protection Dosimetry, vol. 131, no. 4, pp. 521-525, 2008.

[19] M. Whillock and G. Britain, Ultraviolet Radiation Levels Associated with the Use of Fluorescent General Lighting, UV-A and $U V-B$ Lamps in the Workplace and Home, National Radiological Protection Board, 1988.

[20] International Agency for Research on Cancer, "IARC Monographs on the Evaluation of Carcinogenic Risks to Humans," IARC Monograph 100D, Solar and Ultraviolet Radiation, 2012.

[21] B. Roisin, M. Bodart, A. Deneyer, and P. D'Herdt, “On the substitution of incandescent lamps by compact fluorescent lamps: switch on behaviour and photometric distribution," Ingineria Iluminatului, vol. 9, no. 1, p. 50, 2001.

[22] Occupational Exposure Limits, Requirements, Guidelines and Technical Guidance and Environmental Health Center, Institute for Environmental Research, 2011.

[23] S. Safari, M. Kazemi, H. Dehghan, H. A. Yousefi, and B. Mahaki, "Evaluation of ultraviolet radiation emitted from compact fluorescent lamps," Journal of Health System Research, vol. 9, no. 11, pp. 1177-1183, 2013.

[24] T. Mironava, M. Hadjiargyrou, M. Simon, and M. H. Rafailovich, "The effects of UV emission from compact fluorescent light exposure on human dermal fibroblasts and keratinocytes in vitro," Photochemistry and Photobiology, vol. 88, no. 6, pp. 1497-1506, 2012.

[25] M. Rihner and H. McGrath, "Fluorescent light photosensitivity in patients with systemic lupus erythematosus," Arthritis \& Rheumatism, vol. 35, no. 8, pp. 949-952, 1992.

[26] P. T. Stone, "Fluorescent lighting and health," Lighting Research \& Technology, vol. 24, no. 2, pp. 55-61, 1992.

[27] J. M. Elwood, "Could melanoma be caused by fluorescent light? A review of relevant epidemiology," Recent Results in Cancer Research, vol. 102, pp. 127-136, 1986. 

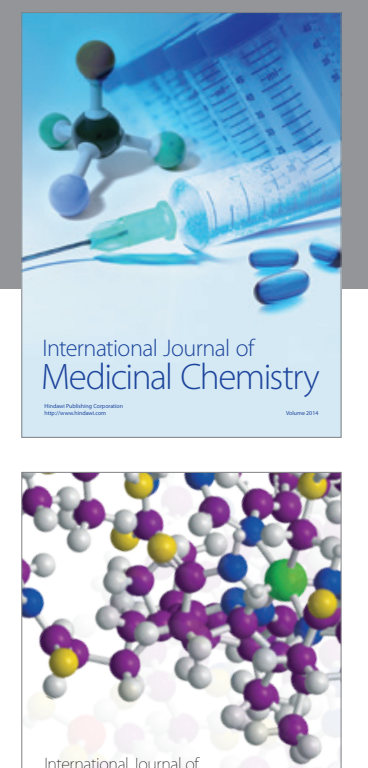

\section{Carbohydrate} Chemistry

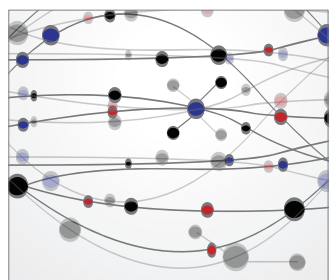

The Scientific World Journal
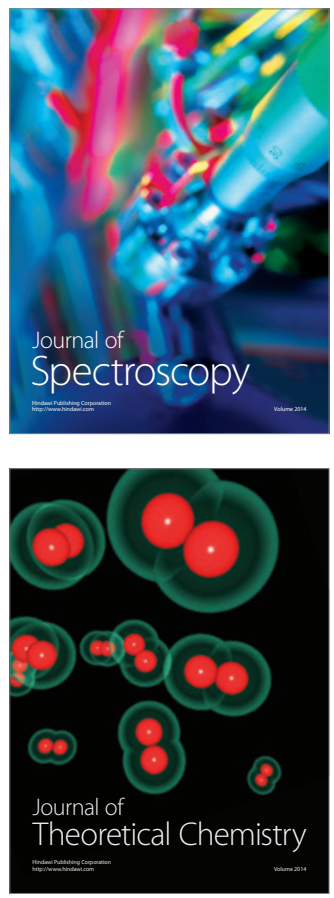
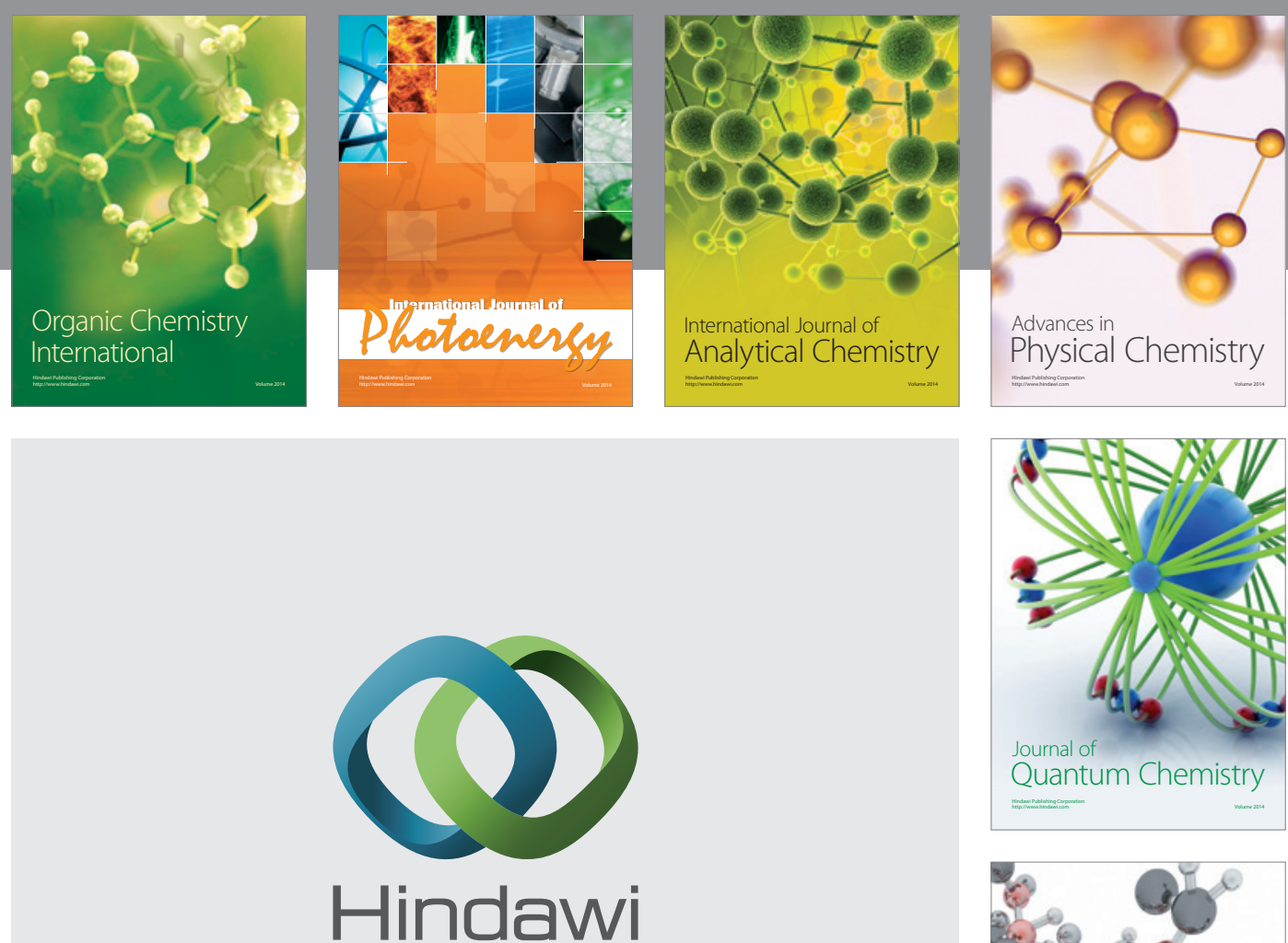

Submit your manuscripts at

http://www.hindawi.com

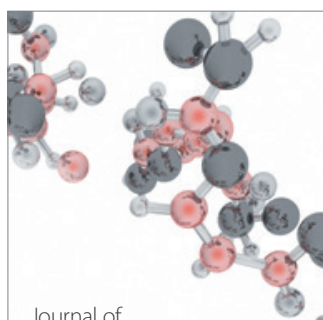

Analytical Methods

in Chemistry

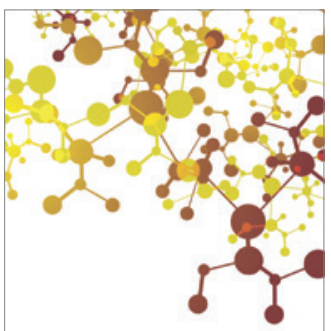

Journal of

Applied Chemistry

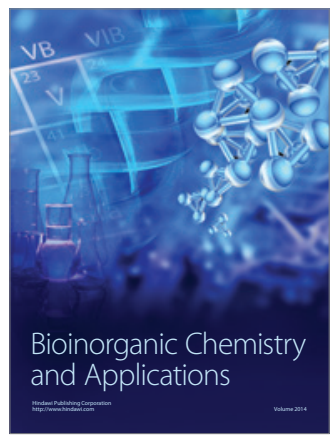

Inorganic Chemistry
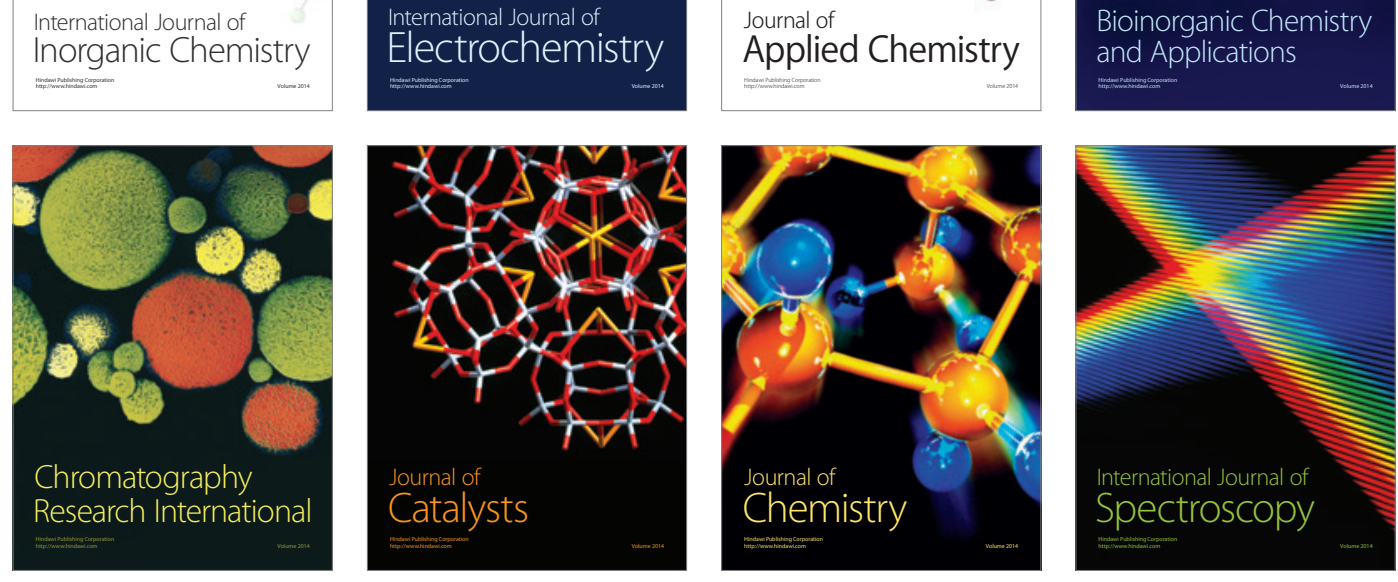